\title{
UFSC COMPETE: COMO CRIAR SINERGIA ENTRE DIFERENTES EQUIPES DE COMPETIÇÕES ESTUDANTIS
}

\author{
Rodrigo de Souza Vieira \\ Universidade Federal de Santa Catarina \\ rodrigo.vieira@ufsc.br
}

\begin{abstract}
Resumo
Apresentamos neste trabalho o programa de extensão UFSC Compete, que se divide em equipes de competição que envolvem alunos de vários cursos da Universidade, cujo objetivo é criar um produto e defendê-lo em uma competição entre outras universidades nacionais e internacionais. Aqui são mostrados o histórico de cada competição e de nossas equipes. São elencados os resultados até então obtidos por esta ação, nas competições e principalmente fora delas, demonstrando sua importância tanto para a formação acadêmica como para a formação pessoal dos seus envolvidos. No final são traçadas novas ações a serem tomadas no sentido de melhorar ainda mais os resultados do programa.

Palavras-chave: Competições estudantis. Competições de engenharia. Formação de engenheiros.
\end{abstract}

\section{UFSC COMPETE: CREATING SYNERGY BETWEEN DIFFERENT STUDENT COMPETITIONSTEAMS}

Abstract

In this paper the outreach program UFSC Compete is presented.This program is divided into competing teams involving students from severalcourses at the University, and its goal is to create and defending a product in a competition against other national and international universities. The history of each competition and our teams are shown. The results of this action, inside and outside competitions are listed, demonstrating their importance for the academic and personal formation of its stakeholders. At the end some future actions are described to improve in the future the results of this Program. Keywords: Student competitions. Engineering competitions.Training engineers.

\section{UFSC COMPETE: COMO CRIAR SINERGIA ENTRE DIFERENTES EQUIPOS DE COMPETIÇIONES ESTUDANTILES}

\section{Resumen}

Este trabajo presenta el programa de extensión UFSC Compete, que se divide en equipos de competición que envuelven alumnos de varios cursos de la Universidad Federal de Santa Catarina con el objetivo de crear un producto y defenderlo en una competición entre otras universidades nacionales e internacionales. Aquí son relatados el histórico de cada competición y de nuestros equipos. Son relacionados los resultados obtenidos por esta acción, en las competiciones, principalmente fuera de ellas, demostrando su importancia tanto para la formación académica cuanto para la formación personal de los envueltos. Al final son delineadas nuevas acciones que serán consideradas con el objetivo de mejorar los resultados del programa de extensión UFSC Compete.

Palabras-clave: Competiciones estudiantiles. Competiciones de ingenierías. Formación de ingenieros. 
UFSC compete: como criar sinergia entre diferentes equipes de competições estudantis

\section{INTRODUÇÃO}

A competição sempre esteve presente na vida dos seres humanos. Sempre nos motivamos a vencer limites e bater recordes. O esporte em geral é uma maneira sadia de competição, onde o mérito sempre está na capacidade de vencer, de forma responsável, ética e legal. As diferentes competições esportivas que existem hoje em nosso mundo sempre tem por objetivo comparar resultados, elegendo o mais apto, o mais rápido, o mais capaz.

Esta ideia de competição acabou sendo trazida para as escolas de engenharia em 1973, através do Recreational-Ecological-Vehicle (REV), concebido pelo Dr. William R. Shapton, na época professor da Universidade de Cincinnati, USA. Tratava-se de uma competição cujo objetivo era projetar e fabricar um veículo todo terreno, anfíbio para dois ocupantes, comumente chamado de All Terrain Vebicle (ATV). No primeiro ano os veículos eram modelos comerciais adaptados pelos alunos, em um total de seis equipes. Já no ano seguinte, 8 universidades participaram desenvolvendo seus próprios projetos.(STEPHENS \&SHAPTON, 1977). Dali surgiria em 1976 a Mini Baja Est, promovida pela Sociedade dos Engenheiros Automotivos SAE, que depois se tornaria Baja $S A E$. Àquela época, 10 equipes participaram da competição.

Com o estreito vínculo da universidade com a indústria no país norte americano, a competição foi crescendo, possibilitando o surgimento de outras, como a Formula SAE em 1981 (6 equipes) (COMPETITION, 2016), SAE Aero Design em 1986 (14 equipes) SAE Clean Snowmobile em 2000 (7 equipes), SAE Supermilage em 1980, and Shell Eco Marathon, que surgiu em 1939 como uma competição entre empregados da empresa e depois se tornou uma competição entre universidades.

Com o tempo essas competições se estenderam e atravessaram os limites dos países de origem chegando inclusive ao Brasil. Surgiram entãoo Baja SAE Brasil, em 1994 como prova nacional e em 1997 com as provas regionais, como a Baja-Sul SAE Brasil. A Fórmula SAE Brasil foi criadaem 2004 com veículos apenas com motor de combustão interna, expandindo para os veículos elétricos em 2012. AAero Design foi criada como competição no Brasil em 1999 e atualmente conta com três diferentes categorias com mais de 100 equipes participantes. O desafio Solar Brasil surgiu em 2009, por iniciativa do Pólo Náutico da Universidade Federal do Rio de Janeiro, baseado no Solar Splash, criado em 1994 nos Estados Unidos. (UFSC COMPETE, 2015)

Aos poucos várias universidades brasileiras, de todas as regiões do país, foram se engajando nessas atividades no sentido de promoverem uma formação mais ampla e melhor para os seus alunos. Assim, as competições de cunho nacional listadas anteriormente passaram a fazer 
UFSC compete: como criar sinergia entre diferentes equipes de competições estudantis

parte da agenda de várias escolas de engenharia,incluindo aí a Universidade Federal de Santa Catarina, localizada na cidade de Florianópolis, no sul do Brasil.

\section{AS EQUIPES NA UFSC}

Buscando proporcionar aos estudantes um aprendizado completo dentro das universidades, as Equipes de Competição vêm crescendo ano após ano em todo o Brasil. Esses projetos têm como objetivo inserir os estudantes em um ambiente de trabalho coletivo, onde os participantes devem aprender sobre projeto, gestão e coletividade, seguindo regras propostas pelas competições das quais participam e aproximando a universidade ao mercado.

As equipes de competição da UFSC campus Florianópolis estão sediadas no Departamento de Engenharia Mecânica, considerado um dos cursos de melhor nível no país, e que detém a maior parte dos graduandos participantes. São elas: Ampera Racing (Equipe de Fórmula Elétrico), Baja UFSC (Equipe de Mini Baja), Céu Azul (Equipe de AeroDesign), e ${ }^{3}$ (Equipe de Eficiência Energética), Fórmula UFSC (Equipe de Fórmula Combustão) e Vento Sul (Equipe de Barcos Solares).

Do ponto de vista histórico, a primeira equipe criada na UniversidadeFederal de Santa Catarina foi a Baja UFSC, atividade de extensão que possibilita aos alunos obter, ampliar e aplicar conhecimentos de diversas áreas, desde a administrativa à técnica, dando carátermultidisciplinar ao projeto e atuando em uma formação cada vez mais completa de seusalunos. Cabe aos alunos projetar e construir um protótipo fora de estrada, confiável, de alto desempenho, baixo custo, comviabilidade de produção em larga escala. Estes pontos são avaliados por juízes pinçados nas indústrias automobilistas do país, o que também serve de um primeiro contato dos alunos com engenheiros já formados, trabalhando em uma área que lhes têm muita afinidade. Atualmente a competição nacional de Baja SAE é um dos maiores eventos competitivosde engenharia do país, no âmbito universitário, com grande visibilidade tanto para os alunosparticipantes, quanto para as Universidades representadas. A Equipe UFSC Baja SAE participa anualmente das competições Regional/Etapa Sul e Nacional/Competição Baja SAE Brasil, sendo a primeira realizada em Gravataí (RS-Brasil), contando com 25 equipes de universidades da região Sul, e a segunda em São José dos Campos (SP-Brasil), contando com 74 equipes de Universidades de todo o país. Representando a UFSC desde 1997, a equipe possui grande destaque no cenário nacional de Baja 
UFSC compete: como criar sinergia entre diferentes equipes de competições estudantis

SAE, sendo heptacampeã da etapa Regional Sul e obtendo boas colocações na etapa Nacional. A equipe da UFSC já se classificou para a etapa Mundial duas vezes (2009 e 2013) e ficou em oitavo lugar na última competição, realizada em março deste ano. Outras premiações, ao longo de sua existência, também contemplaram a equipe, como colocações entre os três primeiros lugares em provas de projeto e dinâmicas.

A equipe Céu Azul aeronaves foi a segunda equipe formada na UFSC. Ele participa da Competição SAE Brasil AeroDesign, que aconteceanualmente no DCTA (Departamento de Ciência e Tecnologia Aeronáutica), na cidade de São José dos Campos-SP. Desde 1999, anoda primeira competição, a UFSC é representada.

Acompetição tem como principais objetivos estimular e dar oportunidade a alunos de obter,aprofundar e aplicar conhecimentos focando o ambiente aeronáutico através de um projeto multidisciplinar desafiador. A cada ano a competição vem crescendo e no ano de 2015 foram inscritas 95 equipes (limite máximo da competição) de universidades de todo o país, além de3 do exterior.Acompetição é dividida em três categorias, a Micro, a Regular e a Advanced, com diferentes requisitos de projeto a serem cumpridos.. Na classe Regular a Céu Azul ficou em $6^{\circ}$ e $7^{\circ}$ lugares em 2006 e 2004, respectivamente. Já na classe Micro, que participou até 2015, conquistou a $2^{\mathrm{a}}$ colocação já na primeira participação, o $3^{\circ}$ lugar em 2014 e foi campeã em 2012. Esta vitória deu a oportunidade à equipe de participar da etapa mundial, no Texas, em 2013, onde conquistou a $3^{\text {a }}$ colocação e o troféu de Maior eficiência estrutural, entre mais de 100 equipes de todo o mundo.

No histórico da competição brasileira recebeu várias menções honrosas, dentre elas: Maior eficiência estrutural, Maior precisão de peso vazio e Melhor inovação tecnológica. Desde 2015 a equipe migrou da Classe Micro para a Advanced, criando novos desafios para os seus alunos.

A e3 - Equipe UFSC de eficiência energética participa regularmente da competição Maratona da eficiência, no kartódromo de Interlagos, São Paulo e, de maneira esporádica, da Shell Eco-marathon Americas, evento que acontece anualmente nos Estados Unidos e reúne equipes de mais de cinco países das Américas, incluindo Estados Unidos e Canadá. Ambas competições estimulam as equipes a desenvolver protótipos com o objetivo de obter veículos que percorram a maior distância com a menor quantidade de energia utilizada. Para isto os alunos aplicam os conhecimentos adquiridos em sala de aula, além de desenvolverem as habilidades multidisciplinares e de trabalho em grupo. A equipe surgiu na UFSC em 2009, e desde então participa da competição nacional, todos os anos, além de ter ido à Shell Eco-marathon Americas 
UFSC compete: como criar sinergia entre diferentes equipes de competições estudantis

em 2012, 2013 e 2014. Em 2012 a equipe obteve a segunda colocação na competição nacional na categoria "protótipo gasolina" e em 2013, na mesma categoria, alcançou a $5^{a}$ colocação na Shell Eco-marathon, obtendo a marca de $418 \mathrm{~km}$ por litro, que é a melhor marca de uma equipe brasileira até hoje. A equipe atualmente conta com um protótipo na categoria gasolina e outro na categoria etanol, complanos para a construção de um novo veículo, movido a energia elétrica.

A Equipe Vento Sul é um grupo multidisciplinar de alunos de graduação e pós graduação da Universidade Federal de Santa Catarina com o objetivo de desenvolver veículos movidos exclusivamente à energia solar fotovoltaica. A equipe é focada no desenvolvimento de embarcações movidas à energia solar, e é hoje uma referência nacional na área, tendo conquistado por Ganos consecutivos o título de Campeã na competição brasileira de barcos movidos a energia solar fotovoltaica:o Desafio Solar Brasil. A equipe também participou três vezes de competição internacional Dutch Solar Challenge, na Holanda, sendo considerada a melhor equipe não europeia em 2010, o barco mais leve em 2012 e $7^{a}$ colocada geral nos anos de 2012 e 2014.

A equipe Fórmula UFSC participa da Competição nacional de Fórmula SAE, queacontece anualmente no ECPA (Esporte Clube Piracicabano de Automobilismo) no interior do Estado de São Paulo. No Brasil, acompetição está em sua $13^{a}$ edição, sendo etapa classificatória para participarda competição na Europa e nos Estados Unidos, que são consideradas as maiores competições mundiais deengenharia automobilística com cunho estudantil. Referenciada como berço de bonsengenheiros, a competição proporciona grande aprendizado, desafiando os alunos a aplicar osconteúdos de sala de aula de forma a obter o melhor projeto.A equipe Fórmula UFSC teve seu início em 2010, obtendo resultados cada vez maissignificativos e ganhando espaço no âmbito nacional e internacional. Atualmente a equipe temum dos projetos de powertrain mais potentes de todo o mundo, sendo pioneira em tecnologiascomo o uso de asas e de turbocompressor em veículos da categoria.

A Ampera Racing desenvolve suas atividades em torno da proposta de projetar, construir e testar um veículo elétrico monoposto de alto desempenho voltado à competição de Fórmula SAE Elétrico. Neste sentido, a equipe capacita seus membros através do conhecimento e das experiências obtidas, uma vez que a competição requer que o produto final tenha aplicabilidade no mercado, seja eficiente e apresente bom desempenho.Dividida em áreas técnicas e de gestão, a equipe proporciona aos participantes contato com problemas reais de engenharia, gestão e trabalho em equipe, aplicando o conhecimento teórico adquirido em sala de aula e complementando as atividades de pesquisa e extensão da Universidade. Com seu primeiro 
UFSC compete: como criar sinergia entre diferentes equipes de competições estudantis

protótipo construído em 2014, a equipe conquistou expressivo $3^{\circ}$ lugar na categoria Elétrico, se estabelecendo como principal equipe da categoria no Sul do país.

\section{UFSC COMPETE NA FORMAÇÃO ACADÊMICA}

Mesmo sendo uma atividade de extensão, a participação de um aluno em uma das equipes do UFSC Compete o ajuda em sobremaneira na sua formação.Tal atividade alinha a Universidade na forte corrente existente atualmente de formação de engenheiros com a aplicação prática de seus conhecimentos, como o conceito CDIO (CRAWLEYet al, 2007) cujo foco principal e proporcionar aos alunos a vivência da engenharia dentro da Universidade. Esta abordagem visa colocar o aluno em problemas reais da vida do engenheiro ainda na sua formação, diferente do modelo passivo de aprendizagem vastamente adotado, no qual o aluno senta e espera que o professor the passe os conceitos por meio de aulas expositivas.

É indiscutível o ganho na formação de melhores engenheiros pois eles saem das universidades mais bem formados. Os alunos passam por um processo de aprendizagem real, contextualizada e com objetivos bem definidos de tempo e produto. Dentro desta linha, pode-se elencar uma série de ganhos na sua formação por meio da criação e manutenção de equipes de competição:

1. Desenvolvimento de soluções inovadoras de engenharia através de protótipos limitadas por regras e regulamentos impostos: os regulamentos específicos de cada prova restringem as possíveis soluções a serem encontradas pelas equipes, forçando portanto a potencialização da criatividade de cada envolvido no projeto. Isto força o aluno a sair da sua zona de conforto, buscando soluções vanguardistas ou otimizadas.

2. Estabelecimento de noções de gerenciamento e organização em trabalhos em equipe: este é um ponto extremamente importante na formação de engenheiros, pois visto o grande desenvolvimento tecnológico, é impossível criar novas soluções sozinho. O trabalho em grupo faz parte do dia a dia do engenheiro moderno e pouca ênfase é dada a isto nas escolas de engenharia. Além disto, equipes de competição envolvem grupos multidisciplinares, como acontece dentro das empresas, envolvendo diferentes áreas do conhecimento humano na busca da resolução de problemas, o que é praticamente impossível de ser "simulado" em uma sala de aulas. Nesta linha a gestão deste grupo a sua comunicação passam a ser trabalhadas mais intensamente, sendo importante elemento complementar à formação técnica. 
UFSC compete: como criar sinergia entre diferentes equipes de competições estudantis

3. Estabelecimento de contato e intercâmbio técnico e de conhecimento entre as equipes: as competições são na verdade um ponto de encontro de alunos que tem a priori uma série de afinidades. É neste cenário que é possível estabelecer a rede de relacionamentos do agora aluno e futuro engenheiro. A participação de um aluno em uma competição deve ser estimulada pois isto lhe abre as portas a um mundo que ele pertence, embora ele ainda não o conheça.

4. Desenvolvimento de de liderança e planejamento: na estrutura das equipes existe a figura do capitão e dos gerentes nas mais diversas áreas, o que força os alunos ao planejamento de suas atividades. Por ter uma restrição muito forte de tempo, em função das datas das competições, os alunos devem planejar e executar suas tarefas para que seja alcançado o objetivo final. Isto também incentiva a definição de metas e ações, além do senso de responsabilidade, que é partilhado por todos os membros da equipe.

5. Incentivo e estímulo do comportamento ético e profissional: por se tratar de uma competição, o objetivo final é vencê-la, mas de forma justa, ética e responsável. Existem regras bem definidas, que devem ser respeitas, assim como seus oponentes durante as provas. Isto não só auxilia na formação de excelentes profissionais, como também na melhoria da sociedade, com o fortalecimento de preceitos indispensáveis na criação de bons cidadãos.

6. Representação da Universidade pela participação de competições nacionais e internacionais: Neste ponto dois desdobramentos são interessantes. O primeiro é o do sentimento de "corpo" do aluno com a Universidade que ele estuda. Ele se sente motivado por estar ali defendendo o seu curso e a formação que lhe foi conferida.Além dissoele se sente responsável em assumir uma postura coerente por saber que carrega consigo o nome da Universidade, ele deixa de ser apenas um aluno, e passa a ser um representante da imagem de sua escola.

7. Extensão de conhecimentos teóricos relativos àformação profissional: As atividades das equipes de competição são complementares àquelas desenvolvidas em sala de aula, ou seja, não se dissocia o conhecimento trabalhado em sala de aula do executado na prática das equipes. O resultado auferido é a melhora da formação profissional dos alunos, mais preparados para a vida prática da engenharia.

8. Aprimoramento de tecnologias existentes: Simulando o mundo competitivo que vivemos, nas competições, as equipes devem estar sempre àfrente das outras para garantir um bom resultado. Assim, novas tecnologias e novas soluções inovadoras devem ser sempre geradas dentro dos laboratórios. A participação de alunos em equipes de competição acaba forçando-os e preparando-os para a assimilação do novo, quebrando paradigmas de velhas estruturas e 
UFSC compete: como criar sinergia entre diferentes equipes de competições estudantis

conceitos. Isto sem dúvida forma profissionais muito mais capacitados para o mutante mercado de trabalho mundial.

9. Desenvolvimento de interdisciplinaridade dentro da Universidade: Por ter em seu cerne alunos de diferentes cursos, o trabalho em equipes de competição estimula a interdisciplinaridade por meio do respeito a formação dos outros e ao estabelecimento de comunicação precisa e eficiente. No caso da UFSC, muito embora a grande massa de alunos que participa das equipes sejam da engenharia, algumas tem em seus quadros alunos de outros centros, como dos cursos de psicologia, administração e design. Esta ação promove a multidisciplinariedade emaior aproximação de alunos dos diferentes cursos, gerando um bom convívio entre todos.

10. Desenvolvimento pessoal e profissional dos membros: é inegável que o aluno que participa de uma equipe de competição se torna um aluno diferente. O senso de responsabilidade, em função de restrições de tempo e de recursos para realização dos projetos já por si só é um fato importante na formação pessoal. Aliado a isto o desenvolvimento de soluções práticas de engenharia dão aos alunos uma formação diferenciada. Para eles o desenvolvimento de um produto não será uma novidade quando saírem da vida acadêmica, o que se traduz em grande diferencial de formação profissional.

Além dos ganhos por parte do aluno, as equipes de competição também propiciam vantagens para a Universidade que a suporta, como:

1. Aumento da produção acadêmica: pois os alunos são estimulados a junto com os professores orientadores dos projetos gerar artigos técnico/científicos visando a participação de feiras e congressos, nacionais e internacionais.

2. Aumento da visibilidade da universidade: ao contar com bons resultados, a Universidade pode utilizar isto em seu favor, como um importante instrumento de marketing, demonstrando sua competências.

3. Consolidação do relacionamento entre Universidade, aluno e comunidade: como comentado anteriormente, as equipes trabalham no sentido de ligar os alunos e envolve-los na comunidade acadêmica e fora dela, por meio de uma ação estimulante. Por ser voluntário, já existe no aluno uma pré disposição do sucesso nesta ação.

4. Incentivo ao ingresso de alunos de ensino médio na Universidade: ao visitar escolas da região e mostrar os seus produtos por meio de feiras e exposições, é incontestável a admiração provocada nos futuros acadêmicos. Ao perceberem o que eles podem fazer dentro da Universidade cria-se uma empatia imediata entre a instituição e o futuro ingresso, eles elegem a Universidadecomo aquela que os propiciará realizar projetos reais já durante a sua formação. 
UFSC compete: como criar sinergia entre diferentes equipes de competições estudantis

5. Integração de Centros e dos campi da Universidade: As competições podem agir como elemento integrador para Universidades multi-campi. No caso da UFSC, atualmente os projetos de equipes de competição vem fortemente sendo desenvolvidos no campus de Joinville, onde existem equipes em todas as competições aqui mencionadas, com resultados também promissores. Ações no sentido de integrar todas as equipes e já existem e hoje há alguma cooperação no desenvolvimento dos seus projetos.

Além do caso de sucesso apresentado na UFSC, existem outras escolas que tem utilizado estes programas dentro de ações de aprendizagem ativa, onde o aluno participa como agende de aprendizagem, tanto fora do país, como no caso das Universidades de Robert Morris (SIRINTERLIKCI, KERZMANN, 2011), Toronto (JONES, 2015), de Coventry (BOOTH, WHITE, 2008), Monterey (RIVERA-SOLORIO, GARCÍA-CUÉLLAR, FLORES, 2013) e o Instituto Tecnológico de Israel (DOPPELT, 2003) como no Brasil, no caso da Universidade Estadual de São Paulo (Ferreira e Caporalli Filho, 2011) e da Universidade Federal de Campina Grande(ARAÚJO et al, 2006).

\section{CONSIDERAÇÕES FINAIS}

Com demonstrado ao longo dotexto, é inegável que as atividades das equipes de competição trazem vários benefícios a toda a comunidade acadêmica, seja na formação, seja na integração, sendo portantode grande importância a manutenção e estímulo de tais atividades. Neste sentido os administradores e professores envolvidos devem prover total suporte institucional, para fortalecer o vínculo do aluno com a instituição.

Além do que fora descrito aqui, as equipes de competição propiciam a conexão com o mundo extra-universidade, promovendo o contato dos alunos com empresas parceiras e apoiadoras dos projetos. Além de permitirem alavancar recursos e serviços para a construção dos protótipos, esta relação Universidade/Empresa cria vínculos institucionais entre os partícipes, possibilitando conexões técnico/científicas que se traduzem em desenvolvimento tecnológico regional, o que é feito com relativo sucesso pelas equipes do UFSC Compete.

Deve-se, no entanto, comentar que o conceito por de trás do UFSC Compete é muito mais amplo do que uma série de grupos de alunos trabalhando isoladamente em diferentes projetos. O Programa UFSC Compete deseja em um futuro próximo aglutinar todas as equipes em um mesmo espaço, catalisando processos sinérgicos de desenvolvimento de projetos e 
UFSC compete: como criar sinergia entre diferentes equipes de competições estudantis

soluções. Várias equipes têm processos e atividade similares que podem ser desenvolvidas em paralelo entre elas, acelerando a busca de soluções, queimando etapas, incrementando a produtividade e a geração de novas tecnologias. Atividades repetitivas poderão ser partilhadas ou mesmo suprimidas em função do contato mais direto entre os alunos.

O processo, iniciado há quase 20 anos atrás, hoje gerou uma série de equipes autônomas que trabalham cada uma sob uma forma gerencial específica. O passo seguinte é unificar estas competências, criando um espaço inovador, voltado para o incremento das competências nos projetos.

Podemos concluir que o envolvimento de uma universidade em um projeto deste tipo reforça a sua imagem de Universidade de Excelência. Ela passa a se tornar uma referência na formação de profissionais mais bem preparados para a vida prática. Muito se comenta no ensino da engenharia que há um descolamento da realidade vivida nas escolas e na indústria, que a visão do conceito de engenharia entre estes dois mundos está diferente. Adotando práticas como esta, de forçar o aluno a encarar um problema real, durante sua formação, minimizam tal deficiência. Isto fica reforçado ainda pelo fato de se tratar de uma competição, ou seja, além de se fazer bem feito, deve-se fazer melhor que os outros para vencer.

Esta é a visão da Universidade Federal de Santa Catarina, apoiar uma formação mais completa e mais engajada nas aspirações do mercado de trabalho, fornecendo mão de obra com capacidade técnica e com visão prática da solução de problemas.

\section{REFERÊNCIAS}

ARAÚJO, T.,PEREIRA, V. G., VALE, L. G. M, SOUSA NETO, J.M.R., LIMA, A.M.N, MARIBONDO, J. F. .Projeto Mini Baja como Estudo de Caso para Instrumentação Eletrônica. Congresso Brasileiro de Educação em Engenharia - Cobenge, 2006, Passo Fundo.

BOOTH, J.G., WHITE. P.(2008) Innovative Curriculum Development within the Motorsport B.Eng course at Coventry University. Engineering Education 2008 International Conference on innovation, good practice and research in engineering education, Loughborough, Inglaterra, 2008

COMPETITION HISTORY. Disponível em < http://www.sae.org/students/ > Acesso em: 28 junho. 2016.

CRAWLEY, E. F., MALMQVIST, J. , ÖSTLUND, J. S., BRODEUR, D. R.Rethinking Engineering Education: The CDIO Approach, Springer. 2007. 
UFSC compete: como criar sinergia entre diferentes equipes de competições estudantis

DOPPELT, Y., Implementation and Assessment of ProjectBased Learning in a Flexible Environment, Int. J. Tech. Des. Educ., 12, 2003

FERREIRA, E.G., CAPORALLI FILHO, A. .Influências do projeto baja sae no ensino da engenharia e no desenvolvimento do aluno. Acessado em 28 de junho de 2016, disponível em $<$ http://acervodigital.unesp.br/handle/unesp/164303?locale=pt_BR>, 2011

JONES, M. L. W. Engaging Complexity And Contradiction: Understanding Formula Sae Through Cultural-Historical Activity Theory in Proceedings of the 11th International CDIO Conference, Chengdu University of Information Technology Chengdu, Sichuan, P.R. China, 2015.

RIVERA-SOLORIO, C., GARCÍA-CUÉLLAR, A. J. e FLORES, A. Design and Construction of a Boat Powered by Solar Energy with the Aid of Computational Tools. International Journal of Engineering Education Vol. 29, No. 2, pp. 380-387, 2013

SIRINTERLIKCI, A., KERZMANN. T.L.Active Learning through SAE Baja Competition. 2011 ASEE Annual Conference, Vancouver, BC, 2011

STEPHENS, J. and SHAPTON, W., Mini-Baja 1977 - An Overview, SAE Technical Paper $780241,1978$.

UFSC COMPETE: Relatório de atividades 2015. 